\title{
Axial eye length measurements pre- and post- laser-assisted in situ keratomileusis using the IOL Master: a pilot study
}

This article was published in the following Dove Press journal:

Clinical Ophthalmology

3 November 2010

Number of times this article has been viewed

\section{Spyridon E Chalkiadakis Georgios A Amariotakis Efstratios A Parikakis Vasileios G Peponis}

Athens Eye Hospital, 2nd Eye Clinic, Athens, Greece
Correspondence: Spyridon E Chalkiadakis Ophthalmiatreio Athens Eye Hospital, Eleftheriou Venizelou 26, I0672,

Athens, Greece

Tel +302103623191

$\mathrm{Fax}+302103608660$

Email spyridon.chalkiadakis@doctors.org.uk
Purpose: A preliminary study in order to test the accuracy of the IOL Master in detecting axial eye length changes after laser-assisted in situ keratomileusis and to correlate the findings with the theoretical ablation depth.

Methods: Pre- and postoperative axial eye length measurements were performed in 10 consecutive eyes that underwent laser-assisted in situ keratomileusis with the Alcon Ladar Vision excimer laser to treat myopic refractive errors ranging from -2.50 to -8.00 diopters of spherical equivalent (mean: $-5.23 \pm 1.30 \mathrm{D})$.

Results: The preoperative axial eye length measurements ranged from $24.53 \mathrm{~mm}$ to $27.78 \mathrm{~mm}$ (mean: $25.80 \pm 1.01 \mathrm{~mm}$ ) and from $24.57 \mathrm{~mm}$ to $27.57 \mathrm{~mm}$ (mean: $25.68 \pm 0.93 \mathrm{~mm}$ ) 1 month after the operation. Preoperative and 1-month postoperative data showed a statistically significant difference $(P<0.05)$.

Conclusions: The IOL Master showed a decrease in the axial eye length measurements that was bigger than the theoretical ablation depth and did not correlate well with it. Such data need to be confirmed by a larger cohort of patients.

Keywords: ablation, biometry, coherence, excimer, interferometry, keratomileusis, laser

\section{Introduction}

José Ignacio Barraquer was an ophthalmologist wildly known as "the father of modern refractive surgery". He invented the microkeratome and developed the surgical procedures of keratomileusis and keratophakia. ${ }^{1,2}$ The former eventually evolved into laser-assisted in situ keratomileusis (LASIK) by Pallikaris et al. ${ }^{3}$ Since then it has been widely used mainly to correct myopic refractive errors, flattening and thinning the central cornea. If the axial eye length from the anterior surface of the cornea to the retina can be measured before and after refractive surgery, a decrease in the axial eye length due to corneal thinning should be detectable. The IOL Master is a device that is able to measure axial eye length using partial coherence interferometry. Its precision in axial eye length measurement has been shown to be greater than older standard techniques, such as ultrasound A-scan. ${ }^{4,5}$ The IOL Master measures the axial eye length from the anterior corneal surface to the retinal pigment epithelium with high resolution and precision, and for this reason it should be able to provide an indirect measurement of the decrease in corneal thickness. For this study, we compared the excimer laser theoretical ablation depth with the axial eye length changes after LASIK.

\section{Materials and methods}

This pilot study comprised 10 eyes from 5 patients ( 1 man and 4 women) who underwent LASIK for myopia in our ophthalmology department. Patient age ranged 
between 25 and 47 years (mean: $33 \pm 6.4$ years). Spherical equivalent refraction ranged from -2.50 to -8.00 diopters (D) (mean: $-5.23 \pm 1.30$ D). An IOL Master Version 5.02 (Carl Zeiss, Jena, Germany) was used to obtain the axial eye length measurements in millimetres ( $\mathrm{mm}$ ). This device is based on a dual beam version of an optical measurement technique known as partial coherence interferometry. Patients were asked to discontinue wearing contact lenses at least 1 month prior to undergoing the first refractive and axial eye length evaluation. Patients with systemic and ocular diseases were excluded from the treatment. The changes in the axial eye lengths were compared with the excimer laser theoretical ablation depth, which ranged from $0.0387 \mathrm{~mm}$ to $0.0984 \mathrm{~mm}$ (mean: $0.0734 \pm 0.0167 \mathrm{~mm}$ ).

\section{Results}

Before LASIK the axial eye length measurements ranged from $24.53 \mathrm{~mm}$ to $27.78 \mathrm{~mm}$ (mean: $25.80 \pm 1.01 \mathrm{~mm}$ ). One month after LASIK, the axial eye length measurements modified between $0.04 \mathrm{~mm}$ and $0.32 \mathrm{~mm}$ (mean: $0.12 \pm 0.10 \mathrm{~mm}$ ). We performed two-tailed hypothesis testing (paired $t$-test) because there was a case of postoperative increase in the axial eye length. The null hypothesis, Ho, assumed no effect, ie, the difference in means equalled zero and it would be either true or false. Nevertheless, we would never accept it but we would simply state that we do not have enough evidence to reject it. We then defined the alternative hypothesis, H1, which would hold if the null hypothesis was not true. After collecting the data, we determined the $P$ value for the median difference of the pre- and postoperative measurements of our population, which represented the probability of obtaining our results, or something more extreme, if the null hypothesis was true. This value could not be interpreted as the probability that the null hypothesis was true. We had to make a decision about how much evidence we required to enable us to decide to reject the null hypothesis in favor of the alternative. Conventionally, we considered that if the $P$ value was less than 0.05 , there would be sufficient evidence to reject the null hypothesis, as there was only a small chance the results would occur if the null hypothesis was true. In our preliminary study the $P$ value was lower than 0.05 (computer output gave 0.011 ) and therefore we rejected the null hypothesis and we stated that the results were significant at the 5\% level. The choice of the cut-off 0.05 significance level of the test was arbitrary. On 5\% of occasions we would incorrectly reject the null hypothesis when it was true. As we believe that the clinical implications of incorrectly rejecting the null hypothesis were not serious, we did not require stronger evidence before rejecting it and we did not lower the significance level. Moreover, we did not perform any averaging in the results.

Finally, it is immediately obvious that the theoretical ablation depth of the excimer laser treatment does not correlate well with the variations in the eyes' axial lengths, as measured with the IOL Master, because, on average, the ablation depth is $0.0734 \mathrm{~mm}$ and the lengths of the eyes change, on average, by $0.12 \mathrm{~mm}$.

\section{Discussion}

The first study published regarding the measurement of the axial eye length before and after an excimer laser procedure was from von Mohrenfels et al. ${ }^{6}$ They measured the axial eye length before and after laser-assisted sub-epithelial keratectomy (LASEK) with the IOL Master and they did not find a statistically significant difference before and 1 month after the refractive surgery. Nonetheless, Rosa et $\mathrm{al}^{7}$ in a later publication did not agree with their conclusions. In their paper they tried to test the accuracy of the IOL Master in detecting axial eye length changes after photorefractive keratectomy (PRK). Their study showed that this device does not correlate well with the theoretical ablation depth. In their discussion they rejected the assumption of von Mohrenfels that a significant correlation between the pre- and postoperative axial eye lengths indicates that a significant difference did not exist between pre- and postoperative values, and we agree with them.

The cornea, made up primarily of collagen in a proteoglycan matrix, is organized as broad $1-2 \mu \mathrm{m}$ thick belts (lamellae) that run parallel to the corneal surface. The lamellae are themselves composed of collagen fibrils that are about $30 \mathrm{~nm}$ in diameter, with center-to-center spacing of about $60 \mathrm{~nm} .{ }^{8}$ The cornea's transparency is generally considered to be a consequence of destructive interference of light scattered in all but the forward direction by the ordered arrangement of the collagen fibers lattice. ${ }^{9}$ Any disturbance to this orderly arrangement results in loss of transparency. ${ }^{10}$ In the postLASIK cornea the backscatter in the stromal component of the flap is lower than that in the residual stroma. This might relate to biomechanical effects: in LASIK surgery the lamellae of the stromal component of the flap are permanently severed at the edges of the flap. ${ }^{11}$ Alternatively, this observation might relate to alteration of the hydration gradient known to exist in the cornea, which increases from anterior to posterior. ${ }^{12}$ Potentially, the interruption of the stroma at the surgical ablation interface might alter this gradient, which in turn affects spacing of lamellae and fibers that might act as backscatter components. 
The IOL Master uses a laser diode emitting an infrared light beam $(\lambda=780 \mathrm{~nm})$ of short coherence light (approximately $160 \mu \mathrm{m}$ ). This laser light is emitted onto a beam splitter, which produces two coaxial beams by means of a fixed reference mirror and a moving measurement mirror. These beams are directed into the eye, where they are reflected at the cornea and the retinal pigment epithelium. Interference between the reflected beam components occurs if the path difference between the partial beams is smaller than the coherence length. The resulting intensity distribution is measured by a photodetector and recorded as a function of the displacement of the measurement mirror. The signal-to-noise ratio (SNR) determines the quality of the measurement. The higher the value is, the better the quality of results. Generally, we accept a scan when the SNR is over 2.0. If it is between 2.0 and 1.6 , then the measurement is considered borderline, and, if it is below 1.6, we reject it. In order to have a definitive axial length, the IOL Master averages the results from 4 to 20 acceptable scans and gives a final number. Nonetheless, it is essential that the operator is well trained to recognize and edit results that the machine may consider valid.

It is worth reconsidering the Rosa et al hypothesis that could explain also our results. First, according to the authors, the effective ablation depth can be more than the planned one because it has been shown that the Munnerlyn formula underestimates the ablation depth. Another hypothesis could be a posterior shifting of the corneal plane. According to the authors, any procedure that circumferentially severs lamellae will flatten the cornea centrally due to an outward force in the periphery that pulls laterally on the center and flattens it.

\section{Conclusions}

Our study fills a gap regarding the capability of the IOL Master to detect variations in the axial length of the eye after a photorefractive operation and particularly LASIK. To the best of our knowledge, this is the first time the question has been addressed. Nevertheless, we must point out that ours is a preliminary study with a limited number of individuals recruited. In order to draw safer conclusions, a bigger number of measurements is necessary. Moreover, a need for further basic research has risen in order to explore the dynamics of the entire eye during a refractive surgery.

\section{Disclosure}

The authors report no conflicts of interest in this work.

\section{References}

1. Barraquer JI. Keratomileusis. Int Surg. 1967;48:103-117.

2. Swinger CA, Barraquer JI. Keratophakia and keratomileusis - clinical results. Ophthalmology. 1981;88:709-715.

3. Pallikaris IG, Papatzanaki ME, Stathi EZ, Frenschock O, Georgiadis A. Laser in situ keratomileusis. Lasers Surg Med. 1990;10:463-468.

4. Kiss B, Findl O, Menapace R, et al. Biometry of cataractous eyes using partial coherence interferometry: clinical feasibility study of a commercial prototype I. J Cataract Refract Surg. 2002;28:224-229.

5. Connors R 3rd, Boseman P 3rd, Olson RJ. Accuracy and reproducibility of biometry using partial coherence interferometry. J Cataract Refract Surg. 2002;28:235-238.

6. Winkler von Mohrenfels C, Gabler B, Lohmann CP. Optical biometry before and after excimer laser epithelial keratomileusis (LASEK) for myopia. Eur J Ophthalmol. 2003;13:257-259.

7. Rosa N, Capasso L, Lanza M, Romano A. Axial eye length evaluation before and after myopic photorefractive keratectomy. J Refract Surg. 2005;21:281-287.

8. Meek KM, Boote C. The organization of collagen in the corneal stroma. Exp Eye Res. 2004;78:503-512.

9. Maurice DM. The structure and transparency of the cornea. J Physiol. 1957; 136:263-286.

10. Griffiths SN, Drasdo N, Barnes DA, Sabell AG. Effect of epithelial and stromal edema on the light scattering properties of the cornea. Am J Optom Physiol Opt. 1986;63:888-894.

11. Roberts C. The cornea is not a piece of plastic. J Refract Surg. 2000; 16:407-413.

12. Komai Y, Ushiki T. The three-dimensional organization of collagen fibrils in the human cornea and sclera. Invest Ophthalmol Vis Sci. 1991;32:2244-2258.
Clinical Ophthalmology

\section{Publish your work in this journal}

Clinical Ophthalmology is an international, peer-reviewed journal covering all subspecialties within ophthalmology. Key topics include: Optometry; Visual science; Pharmacology and drug therapy in eye diseases; Basic Sciences; Primary and Secondary eye care; Patient Safety and Quality of Care Improvements. This journal is indexed on

\section{Dovepress}

PubMed Central and CAS, and is the official journal of The Society of Clinical Ophthalmology (SCO). The manuscript management system is completely online and includes a very quick and fair peer-review system, which is all easy to use. Visit http://www.dovepress.com/ testimonials.php to read real quotes from published authors. 